\title{
Certainty and Critical Speed for Decision Making in Tests of Pedestrian Automatic Emergency Braking Systems
}

\author{
Alberto López Rosado, Member, IEEE, Stanley Chien, Senior Member, IEEE, Lingxi Li, Senior Member, IEEE, \\ Qiang Yi, Member, IEEE, Yaobin Chen, and Rini Sherony, Member, IEEE
}

\begin{abstract}
This paper starts with depicting the test series carried out by the Transportation Active Safety Institute, with two cars equipped with pedestrian automatic emergency braking (AEB) systems. Then, an AEB analytical model that allows the prediction of the crash speed, stopping distance, and stopping time with a high degree of accuracy is presented. The model has been validated with the test results and can be used for real-time application due to its simplicity. The concept of the active safety margin is introduced and expressed in terms of deceleration, time, and distance in the model. This margin is a criterion that can be used either in the design phase of pedestrian AEB for real-time decision making or as a characteristic indicator in test procedures. Finally, the decision making is completed with the analysis of the behavior of the pedestrian lateral movement and the calculation of the certainty of finding the pedestrian into the crash zone. This model of certainty completes the analysis of decision making and leads to the introduction of the new concept of "critical speed for decision making." All major variables influencing the performance of pedestrian AEB have been modeled. A proposal of certainty scale in this kind of tests and a set of recommendations are given to improve the efficiency and accuracy of evaluation of pedestrian AEB systems.
\end{abstract}

Index Terms-Pedestrian protection, active safety margin, prediction model, critical speed for decision making.

\section{INTRODUCTION}

$\mathbf{T}$ HE Transportation Active Safety Institute (TASI) of Indiana University-Purdue University Indianapolis, carried out a large set of tests for pedestrian AEB. Three different sizes of mannequins and their carrier were developed. These mannequins (child, fit and obese) have been designed and tested with two cars in near 1000 tests during a two year periods. Two main types of tests were carried out, activation tests to assess the true positive situations and non-activation tests to assess the false positive situations in which the mannequins were close

Manuscript received January 26, 2016; revised April 3, 2016, June 8, 2016, and July 31, 2016; accepted August 21, 2016. This work was supported by Toyota's Collaborative Safety Research Center (CSRC). The Associate Editor for this paper was S. S. Nedevschi.

A. López Rosado, S. Chien, L. Li, Q. Yi, and Y. Chen are with the Transportation Active Safety Institute (TASI), Indiana University-Purdue University Indianapolis, Indianapolis, IN 46202 USA (e-mail: tonc0128@gmail.com).

R. Sherony is with the Collaborative Safety Research Center, Toyota Motor Engineering and Manufacturing North America, Inc., Ann Arbor, MI 48105 USA.

Color versions of one or more of the figures in this paper are available online at http://ieeexplore.ieee.org.

Digital Object Identifier 10.1109/TITS.2016.2603445

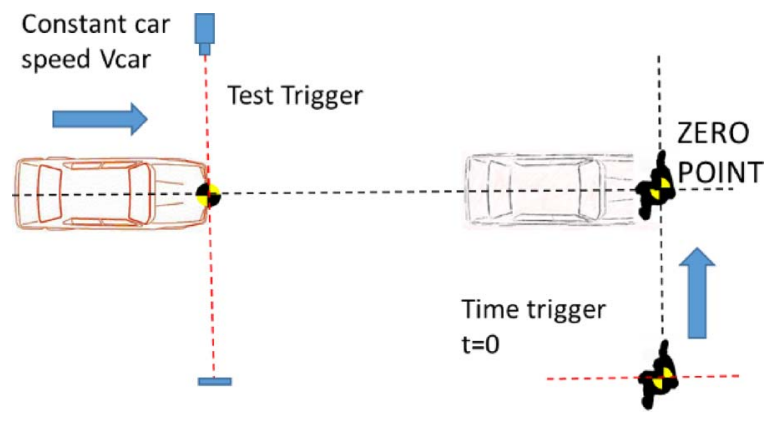

Fig. 1. Pedestrian AEB test setting.

to but did not enter the crash zone. The tests were performed at both day light and at night time. The mannequin movement pattern include standing, moving left to right, right to left and also along and against traffic. The mannequin speeds were 0 , $1.2,1.5$, and $2.2 \mathrm{~m} / \mathrm{s}$. The vehicles' speeds were ranged from $4.46 \mathrm{~m} / \mathrm{s}(10 \mathrm{mph})$ to $22.3 \mathrm{~m} / \mathrm{s}(50 \mathrm{mph})$ in intervals of $2.23 \mathrm{~m} / \mathrm{s}$ ( $5 \mathrm{mph}$ ). A set of sensors, differential GPS, video recording and data acquisition systems were installed to measure all the relevant variables.

Fig. 1 shows a scheme of the test setting.

This paper presents the modeling of decision making and braking phases of the AEB under these tests, analyzing the influencing variables related to the test design and procedure. The goal is to gain a better understanding of the AEB systems under those tests and the improvement of the test procedure accuracy and efficiency. The models presented in this paper can also be used in the design of those systems as they are accurate and simple to run in real time. Many of the test results shown here can be useful themselves for the community of active safety researchers as they are difficult to gather in real carpedestrian crashes. The structure of the paper is the following:

- First a literature review is presented.

- Then the analytic vehicle model is presented for evaluating the braking phase. The model has been optimized and validated with test results. The variation of its main input parameters and output variables, the friction coefficient, the transient response and the low levels of final effective deceleration, are analyzed.

- Using the model, three decision making indicators, based on the Active Safety Margin are defined and tested.

This is the author's manuscript of the article published in final edited form as: 
Finally the decision making phase is described by introducing the concepts of Certainty and Critical Speed for Decision Making (CSDM). Both concepts are calculated and their results are compared with real decision timing recorded in tests. Ranges, maximum and minimum values of numerical data, and statistical distribution of the main factors are presented.

The main scientific contribution of this paper is the new concept and complete analytical modeling of CSDM, the speed beyond which the impact cannot be avoided, based on a novel approach of series expansions of vehicle dynamics equations. The main significant results for the industry are the following:

- The proposal of a new simple and effective scale of Certainty in this kind of tests.

- The analytical expressions applied to the vehicle dynamics model that could be used in real time controllers in real cars.

- The models presented here allow the definition of more accurate test scenarios and test methods for pedestrian AEB systems, including the Certainty among the test variables.

- The background of 1000 tests supporting the conclusions.

\section{Literature REVIEW}

Pedestrian automatic emergency braking has been a subject of intense research and industrial activities in recent years. Good surveys of the research work of such systems can be found in [1]-[5] that provided the analysis of pedestrian crash avoidance by steering and braking. The pedestrian detection technologies were reviewed in [6]-[12] among others. The view of the industrial applications in real cars can be found in [13] and [14]. In [13] Hitoshi stated that the major factor affecting the pedestrian lateral appearance position was whether the driver's view of the pedestrian was blocked by a parked vehicle or other objects. This visual influence was low in the case of crashes involving elderly pedestrians, but important in half of crashes involving children aged 12 or less. According to [14], the vehicle speeds involved in pedestrian crashes were $40 \mathrm{~km} / \mathrm{h}$ or less.

The assessment of the risk in instants prior to the crash has been the object of several analysis, proposals and metrics. In [15] and [16], the authors defined the Time to Collision (TTC) as the simple quotient between the distance to the obstacle and the relative speed of that obstacle with respect to the vehicle, provided that any action is made by the driver to avoid the impact. In [16], the concept of Predicted Minimum Distance (PMD) was defined as the minimum distance between a vehicle and a potential obstacle predicted in real time, assuming constant values in the main variables of vehicle dynamics: turn rate, longitudinal and lateral acceleration. In [16], the authors used the idea of the Required Deceleration (RD) to stop the car in the measured distance of the pedestrian position, and used a first order braking model of the system response obtained from tests. Several concepts assessing the risk in terms of Time-to-X were presented in [17] and [18]. Time to Braking (TTB) was the remaining time until an emergency braking at maximum deceleration must be applied in order to avoid a crash by braking; the authors considered a constant deceleration in braking action. This same idea was extended in [18] to combine steering and braking actions in terms of Time to React (TTR) which is the same idea of Time to Brake (TTB) but applied to four avoidance maneuvers: maximum braking, maximum acceleration, minimum radius steering to the left, and minimum radius steering to the right; the authors defined consequently reaction Time to Brake (TTB), Time to Kickdown (TTK) and Time to Steer (TTS), all of them were particular cases of TTR. Additionally, they also defined Time to Enter (TTE) and Time to Disappear (TTD) that analyze when a car would enter or exits the path of the ego vehicle. Reference [19] presented the concept of Time Difference To Collision (TDTC) which was defined as the time difference for a pedestrian and a vehicle to travel to the potential conflict point if its speed keeps constant. The authors in [20] defined the Post Encroachment Time (PET) as the time differential between when the leading vehicle occupied his location and the trailing vehicle arrived. Reference [21] gave the definition of Deceleration to Safety Time (DTS); it was the necessary deceleration to reach the last calculable PET0 (i.e. when PET $=0$ ), it referred to the position of the first road user, when leaving the conflict area. The second road user may reach this point not earlier than the first road user leaves it. An interesting metric found in [22] defined the Pedestrian Risk Index (PRI) that evaluated the potential severity in both time duration and danger. They use the classical definition of TTC and the Time to stopping $t_{s}$; the difference between them $(\Delta \mathrm{T})$ is used to evaluate the reduction in time for making a safe emergency brake. To assess the severity, they estimated the speed at the impact $V_{i}$ and the PRI which is defined as the summation of the product $V_{i}^{2} . \Delta T_{i}$ during the time of potential conflict between the pedestrian and the vehicle.

In the process of decision making, prior to triggering an emergency braking action, it will be required to calculate the level of certainty/uncertainty about the possible pedestrian entry in the crash zone. For that reason, the kinematics of the pedestrian's movement and its behavior has to be assessed. Indeed, [23]-[25] provided several analyses of the driver and pedestrian reaction times in pedestrian crashes. In [26]-[28] the authors analyzed the difference of pedestrian walking speeds at sidewalks and signalized crosswalks. The effects of season, age and gender of pedestrians were discussed. It was concluded that pedestrian walking speeds at crosswalks were significantly different from those on sidewalks at a 95\% confidence level. In general, pedestrians walk faster at crosswalk compared to on sidewalk and walkway. Reference [29] and [30] demonstrated that the average pedestrian deceleration was about $1.5 \mathrm{~m} / \mathrm{s}^{2}$ and it did not depend much on the walking speed, with a maximum value of $2.5 \mathrm{~m} / \mathrm{s}^{2}$. The stride frequency is about $0.9 \mathrm{~Hz}$ according to [31]. Very similar results $(1 \mathrm{~Hz})$ were published in [32].

Pedestrian behavior models can be found in [33], where Walkim developed a Markov chain model proposing a statistical representation of the pedestrian behavior based in four states (standing still, walking, jogging, and running) with transitions among them. From the former pedestrian state, the model of Walkim calculated the current state. Then, the pedestrian speed vector was split up into the norm and the angle from the 
available information on the statistical distribution of these quantities. Their values follow from the present pedestrian discrete state. The model generates statistically significant pedestrian trajectories and predicts potential car-to-pedestrian impacts. That Markovian model has been applied to Renault vehicles. Researchers from the Daimler group published a model of braking and steering system for pedestrian crash avoidance including the strategies for decision making [5]. The approach of Toyota in this field can be found in [14].

The decision making algorithms could use the calculated severity and risk of fatality of the crash if the speed is too high. The severity, as a function of the impact speed, has been analyzed in [34], where the authors collected a study of 492 pedestrian crashes with passenger cars in Germany resulting in 36 fatalities. They proposed the following mathematical expression to estimate the risk of death as a function of the impact speed $\mathrm{v}(\mathrm{km} / \mathrm{h})$ and the age of the pedestrian. (It is a probability among 0 and 1$) . \mathrm{P}(\mathrm{v}$, age $)=1 /(1+\exp (9.1-$ $0.095 \cdot \mathrm{v}-0.04 \cdot \mathrm{age})$ ).

Finally, the effort in the development of standards for these pedestrian protection systems, common tests procedures, mannequin development, measurement techniques etc., can be seen in [35]-[42], among them the works of the Transportation Active Safety Institute (TASI). Reference [35] and [39] provided a detailed explanation of the test procedure which is modeled in this paper, being this test model the essential new approach of this paper. Reference [37], [38], and [40] gave the details of the mannequin development.

\section{Vehicle Dynamics Model}

\section{A. Test Data Set}

The tests selected to be analyzed in this paper were the following:

- Only AEB activation tests.

- The mannequin movements were only, crossing road from left to right (L/R) or right to left $(\mathrm{R} / \mathrm{L})$.

- Three mannequin sizes (adult fit, adult obese, and child).

- Day light, dark, and dark but lighted conditions.

- The tests were carried out always in dry asphalt and flat surface.

This leads to a set of 426 tests for car A ( $84 \%$ were successful, the car stopped before hitting the mannequin) and 35 tests for car B $(65.7 \%$ successful $)$. Initial speeds $\left(\mathrm{V}_{0}\right)$ were ranged from $4.46 \mathrm{~m} / \mathrm{s}(10 \mathrm{mph})$ to $22.3 \mathrm{~m} / \mathrm{s}(50 \mathrm{mph})$.

For activated AEB cases, stopping time ranged from $0.6 \mathrm{~s}$ to $2.3 \mathrm{~s}$. Stopping distances ranged from $1.5 \mathrm{~m}$ to $18.5 \mathrm{~m}$. The 2nd degree polynomial that fits the stopping distances (426 tests, car A) is the following:

$$
\mathrm{x}_{\mathrm{s}}=-1.52+0.58 \mathrm{~V}_{0}+0.0378 \mathrm{~V}_{0}^{2} \text {. }
$$

The distance from car A to the potential crash point, when the car starts braking $\left(\mathrm{x}_{\mathrm{s} 0}\right)$, was very well correlated with the initial speed, $\mathrm{x}_{\mathrm{s} 0}=-2.9+1.2 \mathrm{~V}_{0}(\mathrm{~m} / \mathrm{s})$. Final positions to the potential crash point once stopped showed an average value of $1.17 \mathrm{~m}$. The standard deviation was $1.44 \mathrm{~m}$.

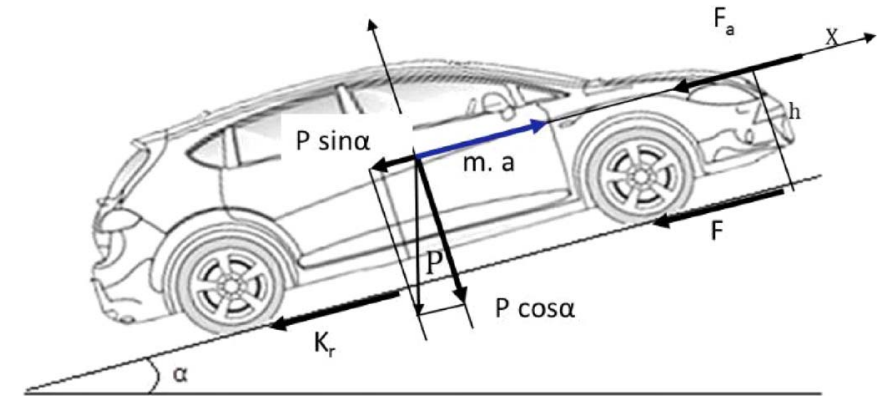

Fig. 2. Vehicle dynamics model.

TABLE I

Terms in the Vehicle Dynamics Model

\begin{tabular}{|c|c|c|c|}
\hline$m$ & \multicolumn{3}{|c|}{ Vehicle mass equivalent, including the rotating masses effect } \\
\hline$a$ & \multicolumn{3}{|c|}{ Vehicle longitudinal acceleration } \\
\hline$x$ & \multicolumn{3}{|c|}{ Longitudinal displacement } \\
\hline$P$ & \multicolumn{3}{|l|}{ Vehicle weight } \\
\hline$F_{a}$ & \multicolumn{3}{|c|}{ Aerodynamic Force $=K_{a} \cdot(d x / d t)^{2}$} \\
\hline \multicolumn{2}{|c|}{$K_{a}=\frac{1}{2} \cdot C_{x} \cdot A_{f} \cdot \rho$} & \multicolumn{2}{|c|}{ Longitudinal aerodynamic drag } \\
\hline$C_{x}$ & \multicolumn{3}{|c|}{ Longitudinal aerodynamic resistance coefficient } \\
\hline \multicolumn{2}{|l|}{$A_{f}$} & \multicolumn{2}{|c|}{ Frontal area of the vehicle } \\
\hline \multicolumn{2}{|l|}{$\rho$} & \multicolumn{2}{|c|}{ Air density } \\
\hline \multicolumn{2}{|c|}{$K_{r}=m \cdot g \cdot f_{r}$} & \multicolumn{2}{|c|}{ Rolling resistance force } \\
\hline \multicolumn{2}{|l|}{$f_{r}$} & \multicolumn{2}{|c|}{ Rolling resistance coefficient } \\
\hline \multicolumn{2}{|c|}{$\begin{array}{l}P \cdot \sin (\alpha) \approx P \cdot \tan (\alpha) \\
=P \frac{d y}{d x}=K_{1} \cdot x+K_{0}\end{array}$} & \multicolumn{2}{|c|}{$\begin{array}{l}\text { Gravitational force, assuming a road with } \\
\text { parabolic profile. In this case it is zero. All } \\
\text { tests were carried out in a flat surface. }\end{array}$} \\
\hline \multicolumn{3}{|c|}{$F=C_{f 3} \cdot t^{3}+C_{f 2} \cdot t^{2}+C_{f 1} \cdot t+C_{f 0}$} & $\begin{array}{l}\text { Braking force input, as a } \\
\text { cubic spline }\end{array}$ \\
\hline$C_{f i}$ & \multicolumn{3}{|c|}{ Coefficients of the braking spline } \\
\hline
\end{tabular}

\section{B. Equations}

To analyze the braking behavior of the car in the tests, following model is developed from the forces equilibrium presented in Fig. 2 leading to the equation (1). Table I describes notations:

$m \cdot\left(\frac{d^{2} x}{d t^{2}}\right)+K_{a} \cdot\left(\frac{d x}{d t}\right)^{2}+K_{1} x+K_{0}+K_{r}+F=0$

The values of $m, C_{x}$, and $A_{f}$ are taken from the technical data sheets of both cars. Equation (1) can be solved numerically, but as the braking time is short, power series expansion can generate very accurate analytical solutions, see [43] and [44].

Assuming the existence of a solution for the displacement as the following:

$$
x(t)=\sum_{n=0}^{\infty} c_{n} t^{n}
$$

where $t$ is time and $c_{n}$ are the series expansion coefficients. 
Taking derivatives, the speed and acceleration series can be obtained and the equation (1) becomes:

$$
\begin{aligned}
& m \cdot\left(\sum_{n=0}^{\infty}(n+1) \cdot(n+2) \cdot c_{n+2} t^{n}\right) \\
& \quad+K_{a} \cdot\left(\sum_{n=0}^{n=\infty}\left[\sum_{n=0}^{n}(i+1) \cdot(n+1-i) \cdot c_{i+1} \cdot c_{n+1-i}\right] \cdot t^{n}\right) \\
& \quad+K_{1} \cdot \sum_{n=0}^{\infty} c_{n} t^{n}+K_{0}+K_{r}+C_{f 3} t^{3}+C_{f 2} t^{2}+C_{f 1} t+C_{f 0}=0
\end{aligned}
$$

with initial conditions:

$$
x\left(t_{0}\right)=x_{0} ; \quad \dot{x}\left(t_{0}\right)=V_{0} .
$$

Collecting (3) in powers of $t$ and equating coefficients to 0 , a linear system of equations is obtained, from which the series coefficients can be obtained too (expanding until $\mathrm{n}=5$ ):

$$
\begin{aligned}
c_{0} & =x_{0} ; \quad c_{1}=V_{0} ; \quad c_{2}=\frac{K_{a} \cdot V_{0}^{2}-K_{r}-C_{f 0}}{2 \cdot m} \\
c_{3} & =\frac{-K_{a} \cdot 4 \cdot V_{0} \cdot c_{2}-C_{f 1}}{6 \cdot m} \\
c_{4} & =\frac{-K_{a} \cdot\left(6 \cdot c_{1} \cdot c_{3}+4 \cdot c_{2}^{2}\right)-C_{f 2}}{12 \cdot m} \\
c_{5} & =\frac{-K_{a} \cdot\left(8 \cdot c_{1} \cdot c_{4}+12 \cdot c_{2} \cdot c_{3}\right)-C_{f 3}}{20 \cdot m} \\
X(t) & \approx C_{0}+C_{1} t+C_{2} t^{2}+C_{3} t^{3}+C_{4} t^{4}+C_{5} t^{5} .
\end{aligned}
$$

This model solution is of closed form, not numerical, and that can help to analyze trends, or the influence of every single factor. Additionally, as it is a simple polynomial of degree 5, its computation is very fast and can be applied for real time simulation.

\section{Braking Input}

The braking force $(\mathrm{F})$ can be expressed as a cubic spline (see Fig. 3) in terms of initial and final slope $\left(\mathrm{F}_{0}^{\prime}\right.$ and $\left.\mathrm{F}_{f}^{\prime}\right)$ and maximum values of time $\left(t_{0}+d\right)$ and braking force $\left(F_{0}+h\right)$ :

$$
\begin{aligned}
& C_{f 3}=\frac{\left(F_{0}^{\prime}+F_{f}^{\prime}\right) \cdot d-2 \cdot h}{d^{3}} ; \\
& C_{f 2}=\frac{1}{2}\left(\frac{\left(F_{f}^{\prime}+F_{0}^{\prime}\right)}{d}-3 C f_{3} \cdot\left(2 . t_{0}+d\right)\right) \\
& C_{f 1}=F_{0}^{\prime}-2 \cdot C f_{2} \cdot t_{0}-2 C f_{2} \cdot t_{0}^{2} ; \\
& C_{f 0}=F_{0}-\left(C f_{1} \cdot t_{0}+C f_{2} \cdot t_{0}^{2}+C f_{3} \cdot t_{0}^{3}\right) .
\end{aligned}
$$

The braking action can be split in two stretches, the transient one (we will call it stretch $\mathrm{T}$ ) during the settling time until $t_{\mathrm{f}}$ and the second one at constant maximum braking force, we

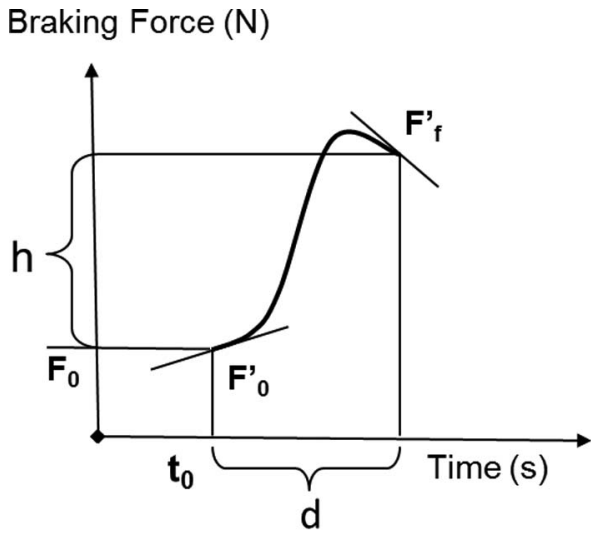

Fig. 3. Braking force spline.

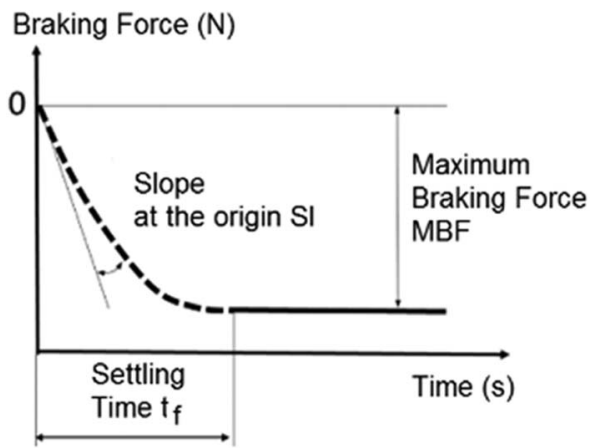

Fig. 4. Two braking stretches.

will call it stationary stretch S, (see Fig. 4). In the first stretch, $F_{f}^{\prime}=F_{0}=t_{0}=0$ so equation (5) becomes:

$$
\begin{aligned}
& C_{f 3}=\frac{F_{0}^{\prime} \cdot d-2 \cdot h}{d^{3}} ; \quad C_{f 2}=\frac{1}{2}\left(\frac{F_{0}}{d}-3 C f_{3 . d}\right) \\
& C_{f 1}=F_{0}^{\prime} ; \quad C_{f 0}=0 .
\end{aligned}
$$

As $x_{0}=0$; the speed in function of time in the first stretch becomes:

$$
V_{T}(t) \approx V_{0}+2 c_{2 T} t+3 c_{3 T} t^{2}+4 c_{4 T} t^{3}+5 c_{5 T} t^{4} .
$$

The second sub-index of $c_{i T}$ refers to stretch $\mathrm{T}$. In stretch $\mathrm{S}$, $\mathrm{C}_{\mathrm{f} 3}=\mathrm{C}_{\mathrm{f} 2}=\mathrm{C}_{\mathrm{f} 1}=0 ; \mathrm{C}_{\mathrm{f} 0}=\mathrm{h}$. As the response in stretch $\mathrm{S}$ is quite flat, we can use a degree 3 displacement so the speed in the second stretch $\left(\mathrm{V}_{\mathrm{S}}\right)$ becomes:

$$
v_{S}(t) \approx v_{f}+2 c_{2 S} t^{\prime}+3 c_{3 S} t^{\prime^{2}}
$$

where $t^{\prime}=t-t_{f} ; v_{f}=v_{T}\left(t_{f}\right)$ and $x_{f}=x_{T}\left(t_{f}\right)$.

The stopping time $t_{s}$, can be calculated from the root of the equation (8) $t_{s S}^{\prime}$, being $t_{s}=t_{s S}^{\prime}+t_{f}$. The lower case sub index $s$ means stopping. The stopping distance is:

$$
x_{s} \approx x_{f}+v_{f} t_{s S}^{\prime}+c_{2 S} t_{s S}^{\prime^{2}}+c_{3 S} t_{s S}^{\prime 3} .
$$

The simulated crash time $\left(t_{c}\right)$ will happen when $x_{S}(t)=x_{p}$, being $x_{p}$ the measured distance to the potential crash point when the car starts braking. The simulated crash speed is $v_{c}=v_{S}\left(t_{c}\right)$. 


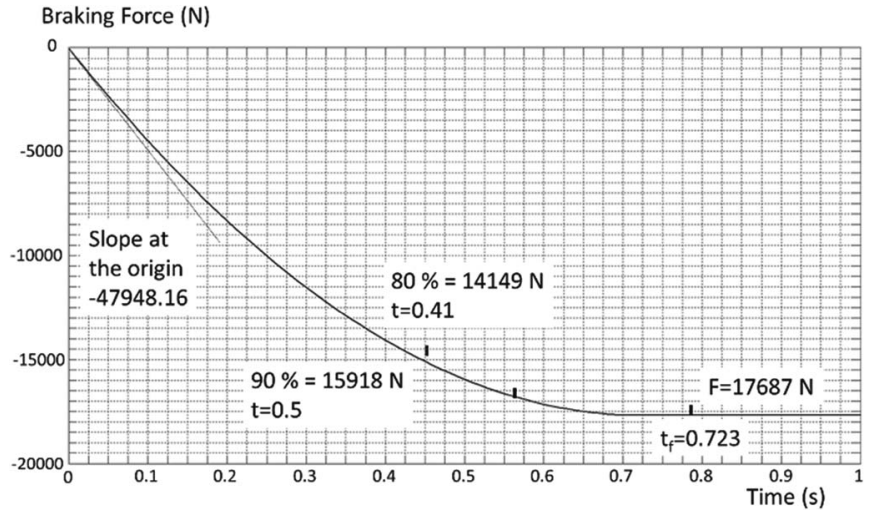

Fig. 5. Average braking force spline for car A.

\section{Optimization and Data Fit}

To fit the outputs of the model to real data, an optimization process was carried out. The fminsearch function in MATLAB, implementing the Nelder-Mead method, was applied. The optimal values of parameters to be found in the optimization were the slope at the origin in the braking force spline, $S l$, (see Fig. 5), the settling time $t_{f}$ and the Maximum Braking Force $(M B F)$. The optimization criterion was the minimum deviation summation in the deceleration signal. The optimal values of initial slope $S l$ and settling time $t_{f}$ were dependent on the vehicle speed. The MBF was not a function of the speed. Fig. 5 shows the average braking spline for car A (mean of 426 tests).

The average slope at the origin was $S l=-47,948 \mathrm{~N} / \mathrm{s}$. The braking force reached its maximum at $t_{f}=0.72 \mathrm{~s}$, which points out the importance of the transient phase. The length of the final constant braking stretch depends on the initial vehicle speed. Constant braking continues until the car stops. The average maximum value of that braking force was $17687 \mathrm{~N}$. At that point, the car starts to slip and the ABS acts keeping the maximum braking force approximately constant. Entering this average braking action as input to the model with the initial speed, we could get the output values of stopping distance and time, simulated speed and decelerations.

\section{E. Accuracy of the Model}

The output values of the model show a very good fit with values measured in AEB testing. Fig. 6 shows the distributions of relative errors in the stopping time when the optimal values for every test are applied. Similar values of relative error can be found in the stopping distances. Results with car B are also accurate. Obviously, if the average braking action is applied, the results are also an average, but they are very good as a general model.

\section{F. Friction Coefficient}

The ABS action limits the braking force. The capacity to brake depends on the available friction potential in the tire-road contact patch. This can change the result of the test by reducing or extending the stopping distance, and so will do in the real performance of the AEB.

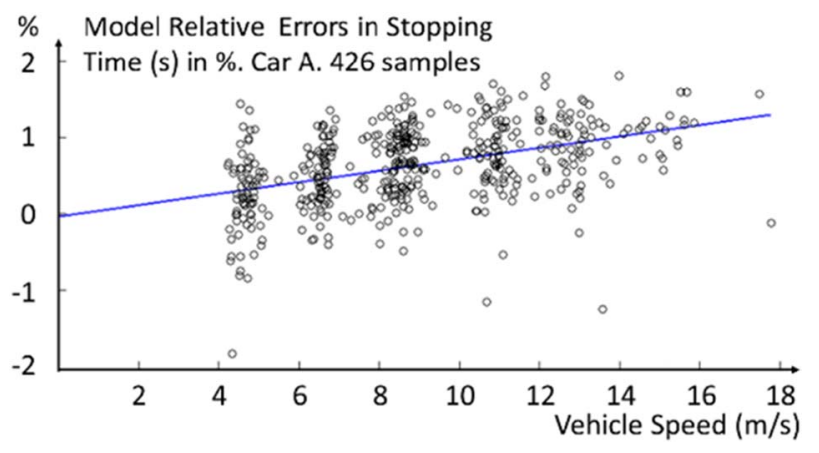

Fig. 6. Relative error in stopping time between real data and simulation.

From the values of MBF derived from testing data, we can obtain an approximation of the effective friction coefficient. The average value is 0.89 and the standard deviation 0.046 (426 tests with car A). The test track was an unused airport runway, the asphalt surface was clean and the average friction is slightly higher than the normal value in open roads $(0.8)$. In series of tests in different tracks, with the same vehicle, this factor could add uncertainty to the results.

\section{G. Importance of the Transient Phase}

The average value of settling time was $0.72 \mathrm{~s}$ and the range of stopping times in this low range of speeds was from $0.6 \mathrm{~s}$ to $2.3 \mathrm{~s}$, which means that the percentage of braking time during the transient phase spans between $35 \%$ and $100 \%$. On an average, at least $50 \%$ of the braking time was transient. For that reason the average effective deceleration was quite low and far from the maximum possible according to the friction potential (see next Section III-H).

\section{H. Low Levels of Effective Deceleration}

The Full Effective Deceleration (FED) obtained in the simulation is the effective final value of deceleration that would stop the car at the same stopping distance in real braking. FED = $-\mathrm{V}_{0}^{2} /\left(2 \mathrm{x}_{\mathrm{S}}\right)$, where $\mathrm{x}_{\mathrm{S}}$ is the braking distance calculated with model (9). Obviously, the distribution of FED is dependent on the vehicle speed, due to the transient time. The regression line is $\mathrm{FED}=-4.4-0.18 \mathrm{~V}_{0}$ for car $\mathrm{A}$ in a Normal distribution $(-5.96,0.6)\left(\mathrm{m} / \mathrm{s}^{2}\right)$. FED $=-3.8-0.25 \mathrm{~V}_{0}$ for car B. The average values of FED $\left(-5.96 \mathrm{~m} / \mathrm{s}^{2}\right.$ for car A and $-5.57 \mathrm{~m} / \mathrm{s}^{2}$ for car B) are much lower than that the average values of maximum point decelerations $\left(-10.11 \mathrm{~m} / \mathrm{s}^{2}\right.$ for car $\mathrm{A}$ and $-9.14 \mathrm{~m} / \mathrm{s}^{2}$ for car B). So the average effective deceleration that can be expected in good dry asphalt with a state of the art passenger car, with excellent ABS braking, is only about $6 \mathrm{~m} / \mathrm{s}^{2}$ in this range of low speeds used for pedestrian crash avoidance tests. At higher speeds the pedestrian is almost always run over.

\section{INDICATORS FOR DECISION MAKING}

To build a complete model of the pedestrian anti-crash system, some indicators are required to establish the decision making strategy in real time if the braking action needs to 


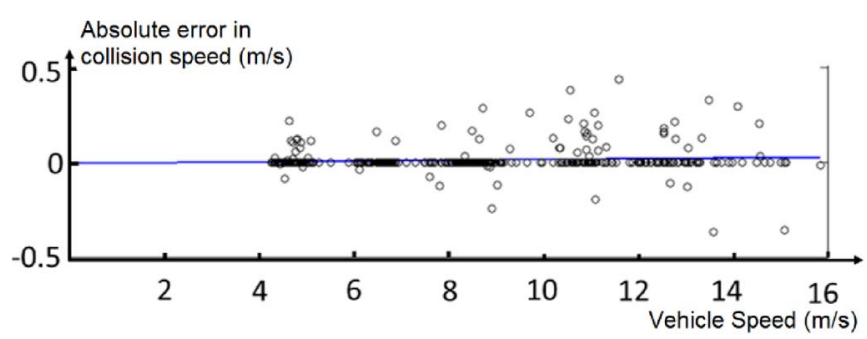

Fig. 7. Absolute error in the impact speed, Car A.

be triggered. Starting from the analytical model presented in Section III, we will define some indicators and use them to predict the occurrence of a crash with the mannequin (pedestrian).

\section{A. Impact Speed}

Assuming that the vehicle knows the distance to the mannequin (measured with the radar) and the vehicle speed, the model presented in Section III can calculate in advance the impact speed. As depicted in Fig. 7, the predicted impact speeds show a very low error compared with the real measured impact speeds for car A.

\section{B. Active Safety Margin}

The Active Safety Margin (ASM) can be defined in terms of deceleration, time, or distance, denoted as ASM_A, ASM_T and ASM-D, respectively.

$$
\text { ASM_A = FED-Astop. }
$$

FED describes how much the car can brake in a given time and Astop shows how much acceleration is needed to stop the car before hit the mannequin. FED is calculated with the model presented in Section III.

Astop $=V_{0}^{2} /(2 \mathrm{DTP})$ is a function of the current initial speed $V_{0}$ and the Distance to the Pedestrian (DTP) when braking starts. As the solution to the model is analytical and a simple polynomial [see equation (4)], it can be calculated easily in real time. The unit of the ASM_A is $\mathrm{m} / \mathrm{s}^{2}$.

When the car is running at speed $V_{0}$ and the pedestrian is detected at a distance DTP, if ASM_A $>0$ the car would be able to stop before impacting the pedestrian (Avoidance), the braking action could wait longer. If ASM_A $<0$, the crash will happen for sure, but with reduced speed and hence with reduced severity of injuries (Mitigation), which is very important.

As the friction coefficient in every test is not known a priori, an average braking action like the one shown in Fig. 5 can be used; Fig. 8 shows the real test impact speed versus calculated ASM_A. In every real test case, a point depicts the calculated ASM_A and the real impact speed. If the result is avoidance, the points have 0 impact speed. All tests with avoidance' results are points covered with an arc in the ASM_A axis around 0 and 2.

In the area of ASM_A $\geq 0$, all test results are supposed to be avoidance and that is true in 352 out of 357 (true avoidances), so the prediction of this indicator is correct in $98.6 \%$ of the avoidance tests.

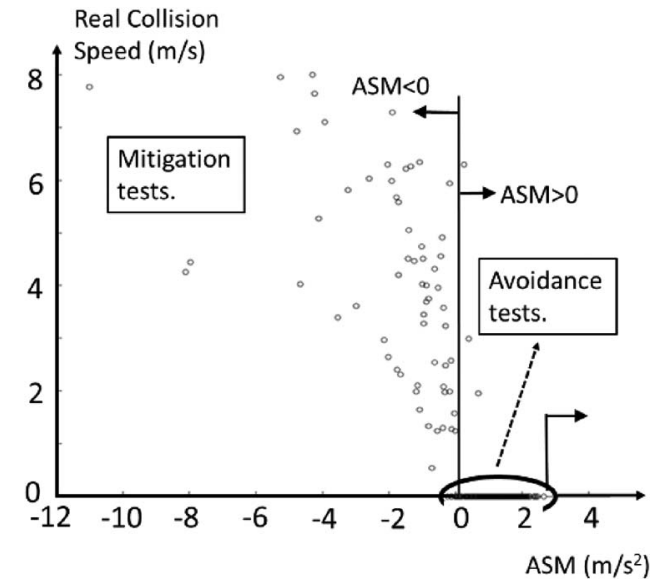

Fig. 8. Active safety margin in terms of deceleration, Car A.

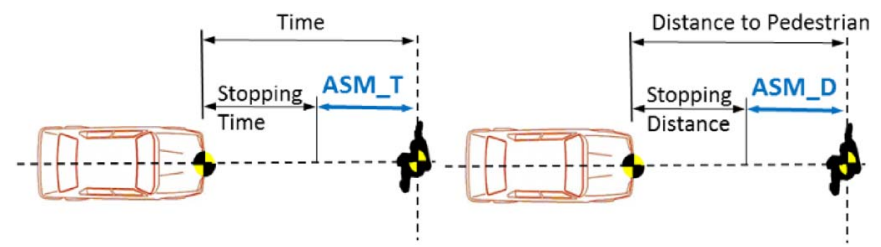

Fig. 9. Active safety margin in terms of distance and time.

The prediction of avoidance tests is wrong (false avoidances) in 5 out of $357(1.4 \%)$. In the area of ASM $<0$, all test results are supposed to be mitigation or full speed crash and that is true in 66 out of 69 , so the prediction of this indicator is correct in $95.7 \%$ of the mitigation tests (true mitigations). The prediction of the mitigation tests is wrong in 3 out of 69 (4.3\%) (False mitigations). An interesting remark is that there are no braking actions beyond ASM_A $>2.6 \mathrm{~m} / \mathrm{s}^{2}$, this gives a first indication of the decision making strategy. This indicator is really accurate to predict the likelihood of the crash with the pedestrian.

\section{Active Safety Margin in Terms of Distance and Time}

The Active Safety margin can also be expressed in terms of distance (ASM_D) and it can be defined as the difference between the distance to the pedestrian (DTP) and the required distance to stop (DTStop) calculated using the model presented in this paper. The unit of ASM_D is meter. Fig. 9 shows the concepts of ASM_D and ASM_T.

$$
\text { ASM_D = DTP }- \text { DTStop. }
$$

The ASM_T indicates how much time the car can continue at the current constant speed without start braking before the crash will be unavoidable. The unit of ASM_T is second.

$$
\text { ASM_T }=\text { ASM_D } / V_{0} \text {. }
$$

Fig. 10 shows the test results of vehicle A with respect to ASM $-T$. It can be seen in this series of real tests, $73 \%$ of crashes can be avoided if the car could start braking only $0.2 \mathrm{~s}$ 


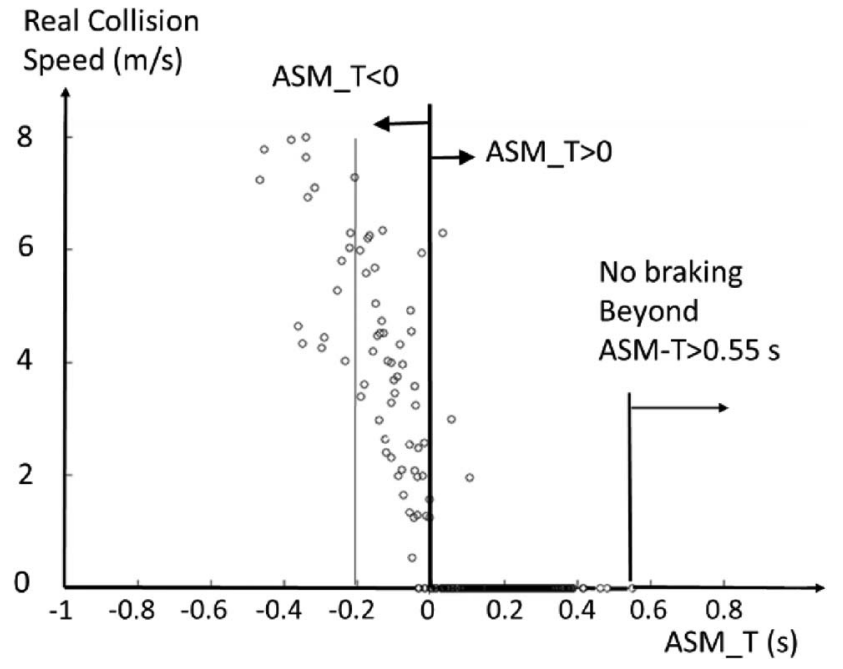

Fig. 10. Active safety margin of car A in terms of time.

earlier. This underlines the importance of an early recognition and the subtle equilibrium between avoiding impacts and preventing false positive triggers of the system at the same time.

The concept of ASM_T presented in this paper is also known as Time to Risk, which is not the same as the Time to Collision (TTC) presented in crash avoidance and active safety literature. The test results also showed that there were no braking actions beyond ASM_D $>4.8 \mathrm{~m}$ or ASM-T $>0.55 \mathrm{~s}$. This gives another indication of the decision making strategy. ASM_A, ASM $-T$ and ASM $-D$ calculated according to the analytical model presented here, are excellent predictors of the crash and they are simple enough to be used in real time. The ASM_A measured in terms of deceleration has two additional advantages:

- Its value does not depend on the speed.

- It can be used in combined braking/steering actions in terms of lateral active safety margin combined with this longitudinal ASM_A.

The results shown in Fig. 10 have been obtained based on braking with the average Maximum Braking Force $(M B F)$ by using the average effective friction coefficient $(A E F C)$ equals 0.89 . The value of the $A E F C$ was known after testing the car. In general, some hypothesis of the value of the AEFC has to be made for real time prediction. If value $=0.8$ is accepted as normal in dry conditions in open roads, the same method of computing the ASM_A can be used with that value, just adjusting the variable $h$ in equation (5).

\section{LATERAL BeHAVIOR AND DECISION MAKING}

\section{A. Introduction}

The decision of triggering an emergency braking in a general driving situation has been analyzed in the models presented in [5], [14], and [44], among others. Those models are well adapted to general driving situations. In the case of a more controlled environment as it happens in performance tests, some simplifications can be assumed. As the motion direction

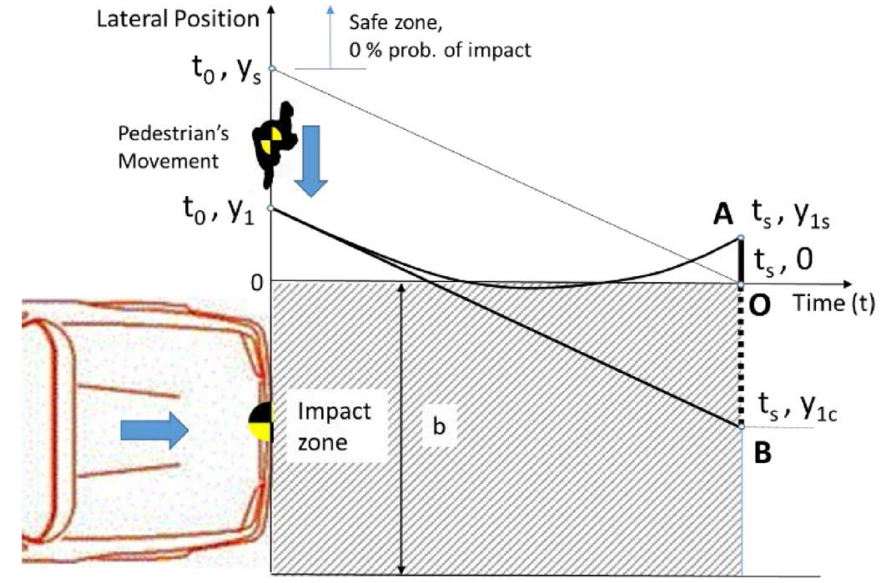

Fig. 11. Analysis of the uncertainty in the pedestrian behavior.

of the pedestrian is always perpendicular to vehicle's trajectory, the braking decision can be split based on two independent indicators. First, the longitudinal active safety margin (ASM) has to reach a certain threshold value, close to 0 . In addition, once that value is reached, the probability of the pedestrian to be in the impact zone (IZ) when the car gets the zero point should be as high as possible to avoid false positive situation. It is assumed that the width of the impact zone (IZ) is $b$ that equals the total width of the car plus two segments of $30 \mathrm{~cm}$ (due to the thickness of pedestrian's body and the position of the feet/legs), one before the Center of Gravity of the pedestrian enters the IZ and the second one after exiting the IZ (See Fig. 11).

\section{B. Model of Certainty}

To evaluate the probability of a pedestrian being in an impact zone (IZ), following are assumed:

- The normal gait frequency of a pedestrian is 2 steps/ sec according to [31], [32], the step length is $v_{p} / 2 \mathrm{~m}$, where $\mathrm{v}_{\mathrm{p}}$ is pedestrian's speed in $\mathrm{m} / \mathrm{s}$.

- The average pedestrian's deceleration is about $1.5 \mathrm{~m} / \mathrm{s}^{2}$ according to [29], [30].

- If the pedestrian notices the vehicle prior to enter the IZ, the pedestrian will try to stop with a constant deceleration. Otherwise it is assumed that the pedestrian will enter the IZ at the same constant speed. Only these two normal pedestrian behaviors are considered. Turnarounds after exiting the IZ or accelerating for passing the IZ are excluded.

According to assumptions above, we propose the scheme shown in Fig. 11 to analyze pedestrian's movement before entering the IZ. When ASM $=0(\mathrm{t}=0$ in Fig. 11), the time for the vehicle to reach the zero point equals the time to stop $\left(t_{s}\right)$. The lateral distance of the pedestrian to the IZ $\left(\mathrm{y}_{1}\right)$, pedestrian's speed $\left(v_{p}\right)$ and the longitudinal distance of the vehicle to crash point, is measured continuously by the vehicle.

If the pedestrian starts above position $y_{s}$, the pedestrian cannot reach the IZ in a normal behavior at the time $t_{s}$ with a constant speed, the pedestrian can at most be at point $\left(t_{s}, 0\right)$ at the time $\mathrm{t}_{\mathrm{s}}$. If the pedestrian is at positions between $\mathrm{y}_{\mathrm{s}}$ and $\mathrm{y}_{1}$, 


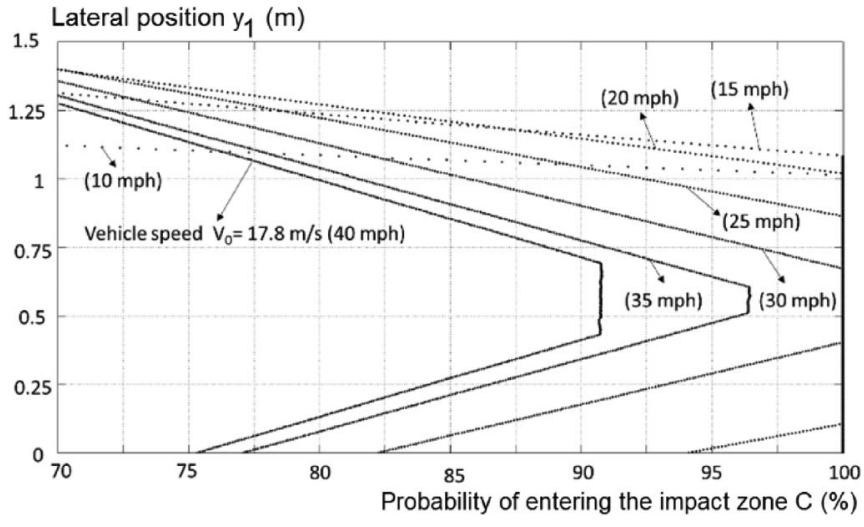

Fig. 12. Analysis of the certainty in the pedestrian movement.

the probability of being inside the impact zone at time $t_{\mathrm{s}}$ (for example in $\mathrm{y}_{1}$ ) is the same as the distance ratio (OB/AB) assuming a constant density distribution of the probability in the pedestrian deceleration value. We will call the probability of being inside $\mathrm{IZ}$ at the time $t_{s}$ as "certainty" $\mathrm{C}$ in this paper, $\mathrm{C}=\mathrm{OB} / \mathrm{AB}$.

With those hypothesis, Fig. 12 shows the value of the lateral position $\mathrm{y}_{1}$ as a function of $\mathrm{C}$ and the vehicle speed $\mathrm{V}_{0}$ in increments of $2.26 \mathrm{~m} / \mathrm{s}(5 \mathrm{mph})$, being $\mathrm{v}_{\mathrm{p}}=1.5 \mathrm{~m} / \mathrm{s}$ and the value of pedestrian deceleration $\mathrm{A}_{\text {ped }}=1.5 \mathrm{~m} / \mathrm{s}^{2}$. An analytical expression of $\mathrm{C}$, as shown in (12), can easily be obtained.

$$
\begin{aligned}
A O & =y_{1 s}=y_{1}-\left(v_{p} \cdot t_{s}-\left(\frac{1}{2}\right) A_{\mathrm{ped}} \cdot t_{s}^{2}\right) ; \\
y_{1 c} & =y_{1}-v_{p} t_{s} ; \quad A B=y_{1 s}-y_{1 c} \\
C & =\frac{O B}{A B}=-y_{1 c} /\left(y_{1 s}-y_{1 c}\right) .
\end{aligned}
$$

Fig. 12 has been obtained using the Monte Carlo method. We have selected that value of $A_{\text {ped }}=1.5 \mathrm{~m} / \mathrm{s}^{2}$ in a constant distribution to fit best the results shown in Fig. 12 corresponding to a pedestrian speed of $1.2 \mathrm{~m} / \mathrm{s}$ and those corresponding to $v_{p}=1.5 \mathrm{~m} / \mathrm{s}$. Other density functions were tried, (normal distributions of the value of $A_{\text {ped }}$ and truncated distributions of that value) and the results are different in the final figures of certainty $\mathrm{C}$, but there is an important lack of published data about real behavior of pedestrians in the pre-crash time in real crashes for obvious reasons; a more sophisticated model of statistical distribution of these pedestrian's actions or behavior in that situation, could fall in the field of speculation. Additionally, the final results would be lower or a higher value of $\mathrm{C}$ for a given lateral position of the pedestrian at $\mathrm{t}_{0}$, but the decision has to be made from a certain threshold of $\mathrm{C}$ anyway. The numeric value of that threshold would change if the pedestrian behavior model is different but the concept would be the same, I.E.: decision making from values, longitudinal ASM and lateral C as we will see at point $\mathrm{D}$. This model can be used with different types of moving objects (cyclists, animals, etc.) using their own kinematic properties and statistical distribution of accelerations. If $\mathrm{A}_{\text {ped }}$ is not a constant, but a statistical variable, the Monte Carlo method should be applied. The results shown in Fig. 12 can change significantly depending on the value of
$\mathrm{A}_{\text {ped }}$, and the statistical distribution, according to the supposed pedestrian's behavior.

\section{Critical Speed for Decision Making (CSDM)}

Fig. 12 relates lateral position of the pedestrian when the car should start braking to avoid the impact, with the probability of the pedestrian to be within the IZ when they meet at the end of the braking in a general case. The kinematic relation between pedestrian and car movement forced by the test setting is not considered in this figure. So when the car should start braking, the pedestrian could initially be anywhere.

From Fig. 11 and equation (12), we can easily obtain the following relation between $\mathrm{y}_{1}, \mathrm{C}$ and $\mathrm{t}_{\mathrm{s}}$ :

$$
y_{1}=v_{p} \cdot t_{s}-C \cdot\left(\frac{1}{2}\right) \cdot A_{\mathrm{ped}} \cdot t_{s}^{2} .
$$

If $V_{0}$ is constant, $\mathrm{t}_{\mathrm{s}}$ is constant too so the set of straight lines shown in Fig. 12 is obtained for different values of initial speed of the vehicle. In Fig. 12 it can be observed that there is a limit in the vehicle speed to any specified level of probability that the pedestrian to be in IZ. Above that speed, the specified probability level will not hold and hence the decision of braking cannot be made for that specified level of probability. For example, when a braking decision is made at $\mathrm{C}=95 \%$, the vehicle can avoid crash when the vehicle speed is less than $16.26 \mathrm{~m} / \mathrm{s}=36.5 \mathrm{mph}=58.5 \mathrm{~km} / \mathrm{h} . \mathrm{C}=95 \%$ cannot be true when vehicle speed is greater than $36.5 \mathrm{mph}$.

The emergency braking maneuver cannot be triggered with a high probability of a false positive action. Thus in high speeds the car needs time to brake but cannot make braking decision (even though it can recognize the pedestrian early) until too late for avoiding crash. In high vehicle speed situations, only mitigation strategies are possible because the decision simply cannot be made. The vehicle speed for separating the complete crash avoidance and crash mitigation at a given certainty level is defined as the Critical Speed for Decision Making (CSDM).

If the road is wet, the time to stop is longer and the CSDM value is lower. Obviously, for the driver it is strongly recommended to reduce the speed if there are pedestrians close to the road. The critical speed condition is at $\mathrm{y}_{1 c}=-b$, (see Fig. 11) since $\mathrm{C}$ cannot be higher when $\mathrm{y}_{1 c}>-b$. From equation (12), we can easily conclude that the time to stop at the CSDM (we call it Critical Stopping Time for Decision Making, CSTDM) is:

$$
\operatorname{CSTDM}=\sqrt{\frac{2 . b}{A_{\text {Ped }} \cdot C}} .
$$

With $0 \leq \mathrm{C} \leq 100 \%$. The initial speed corresponding to that value of CSTDM can be obtained using the model in equations (8) and (9).

The CSTDM and CSDM do not depend on the pedestrian speed but they change very fast with its deceleration $\left(A_{\text {ped }}\right)$. Fig. 13 shows the values of CSDM versus Certainty (in \%) at different pedestrian deceleration values. It can be seen that if the system wants to avoid false positive situations, (accepting only high values of Certainty, $C>95 \%$ ), the maximum initial 


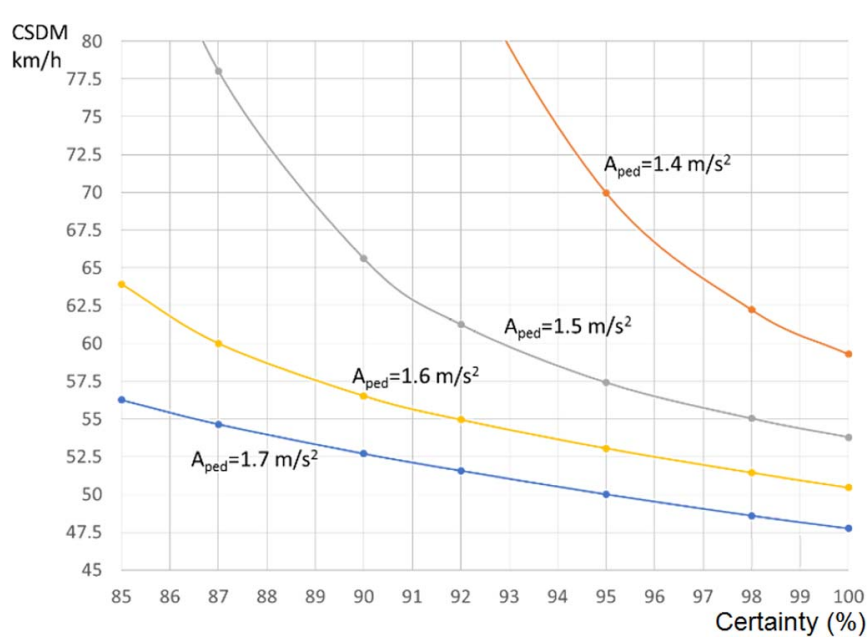

Fig. 13. Critical speed for decision making versus certainty at different levels of pedestrian deceleration (a).

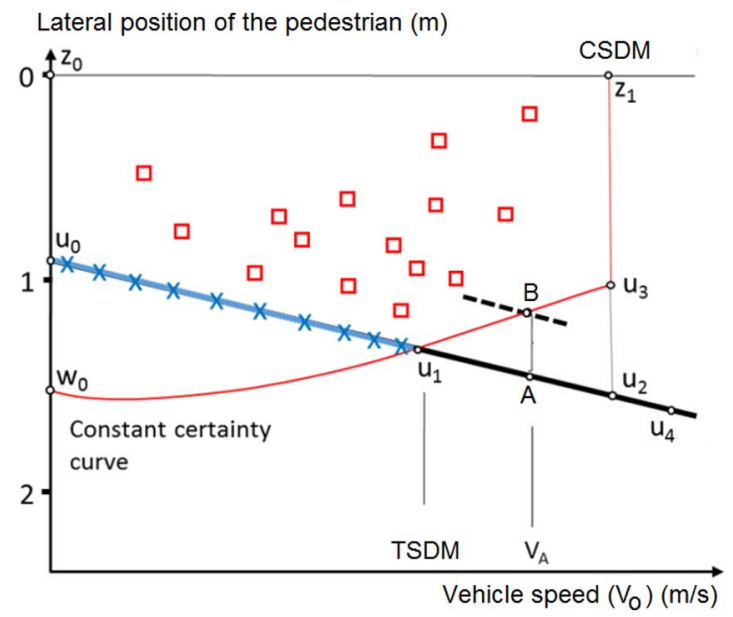

Fig. 14. Regions in the decision making model.

speed of the car (CSDM) must be low, otherwise the decision of emergency braking must be delayed assuming only a final result of mitigation.

All pedestrian AEB tests carried out by the TASI (almost 1000 tests) have been made on dry asphalt. The maximum vehicle speed resulting in a complete avoidance was $15.74 \mathrm{~m} / \mathrm{s}=$ $35.3 \mathrm{mph}=56.67 \mathrm{~km} / \mathrm{h}$. In return all the 136 non-activation tests were negative; both test cars were completely effective in preventing false positive actions. It means that indeed the selected levels of Certainty were very high.

In equation (13), If $C$ is constant, the initial speed and every corresponding $t_{\mathrm{s}}$ are variable obtaining the family of constant certainty curves (see the parabolic curves in Figs. 14 and 15).

When the car moves to the longitudinal position of ASM $=0$ (it is the last opportunity to start braking with full crash avoidance at the speed $\mathrm{V}_{0}$ in a braking time $\mathrm{t}_{\mathrm{s}}$ ), the decision has to be made, but can only be made with a level of certainty $\mathrm{C}$ or higher to avoid the crash if the distance of the pedestrian to the IZ $\left(\mathrm{y}_{1}\right)$ is equal or smaller than the value of $\mathrm{y}_{1}$ according to (13), and the speed is lower than the CSDM value.

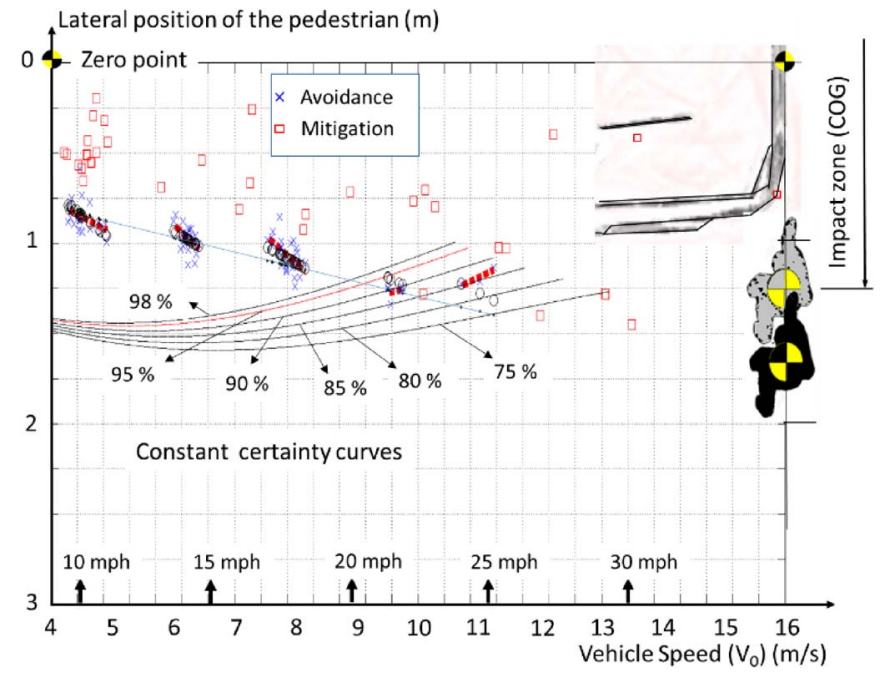

Fig. 15. Lateral position of the pedestrian when the car starts braking.

\section{Uncoupled Decision Making Model}

The braking decision making can be decoupled when the path of the pedestrian is perpendicular to the vehicle path. For every initial speed of the car, there are two associated values of stopping time $t_{\mathrm{s}}$ and stopping distance $\mathrm{x}_{\mathrm{s}}$ according to (9) when $\mathrm{ASM}=0$.

In the designed setting for this real test, the lateral position of the pedestrian is related with the longitudinal position of the car stopping distance $\mathrm{x}_{\mathrm{s}}$.

$$
y_{1}=v_{p} \cdot x_{s} / V_{0}-b / 2 .
$$

The shorter pedestrian lateral position means the shorter longitudinal distance between the car and the pedestrian if they move at constant speed and do crash.

Thus, in Fig. 14, the line $\mathrm{u}_{0}-\mathrm{u}_{4}$ defines the true lateral positions of the pedestrian in the real test as it is designed for different vehicle initial speeds when the car should start braking for full avoidance. Above the line $\mathrm{u}_{0}-\mathrm{u}_{4}$, the pedestrian is closer to the vehicle, meaning that the ASM-T $<0$ when the car starts braking; in that case the best braking result can only be mitigation (e.g., shown by square markers). Below the line $\mathrm{u}_{0}-\mathrm{u}_{4}$, ASM-T $>0$ and the braking decision can "wait" since there is still time for condition changes. The parabola $\mathrm{w}_{0}-\mathrm{u}_{1}-\mathrm{u}_{3}$, is the constant certainty relation for a given level of certainty $\mathrm{C}_{\mathrm{i}}$. It depicts the lateral positions where the pedestrian should be at every speed when ASM_T $=0$, to have a certainty $\mathrm{C}_{\mathrm{i}}$ of being in the IZ. Lower constant certainty values lead to lower curves (see the family of parabolic curves in Fig. 15.

In this ideal theoretical model, if the pedestrian is recognized early, the decisions of braking with final result of full avoidance ( $x$ markers) should be made on the ASM $=0$ segment $u_{0}-u_{1}$. If the recognition was late, the decision points would be found above line $\mathrm{u}_{0}-\mathrm{u}_{4}$ resulting in mitigation (square marks). The car speed corresponding to $\mathrm{u}_{1}$ is the highest speed to avoid crash with certainty $\mathrm{C}_{\mathrm{i}}$, we will call it Test Speed for Decision Making (TSDM). In the speed range corresponding to the range 
of $\mathrm{u}_{0}$ and $\mathrm{u}_{1}$, the car can fully avoid the crash with a level of certainty $\mathrm{C}_{\mathrm{i}}$ (or higher). If $\mathrm{C}_{\mathrm{i}}$ curve is the lowest threshold value of Certainty acceptable to avoid false positive actions, all tests beyond TSDM will end only in mitigation although the recognition is early since the decision of triggering the automatic braking cannot be made because $\mathrm{C}$ is below desired certainty level $\mathrm{C}_{\mathrm{i}}$.

In order to find the limit stopping time $t_{\text {slim }}$ at the TSDM, the intersection between equation (14) and line $\mathrm{u}_{0}-\mathrm{u}_{4}$ should be found. Introducing the value $y_{1=} v_{p} \cdot t_{s}-C \cdot(1 / 2) \cdot A_{\text {ped }} \cdot t_{s}^{2}$ on the left side of equation (14) the value of $t_{\text {slim }}$ and consequently the TSDM can be obtained. Unlike the CSDM, the TSDM depends on the pedestrian speed $\mathrm{v}_{\mathrm{p}}$.

If the recognition is late, the decision is not made on time, the car continues some time $t_{c}$ at a constant speed and the resulting position of the pedestrian is closer when the Certainty threshold is reached and braking starts (see point B), but the result will only be mitigation.

\section{E. Tests Results}

Fig. 15 shows the results of 116 tests carried out with car A. Mannequin's speed was $1.2 \mathrm{~m} / \mathrm{s}$. The results of 35 of them were mitigation and 81 were fully avoided.

The dashed line (almost hidden under the black circular points) shows the regression of the lateral position of the mannequin ( $\mathrm{x}$ marker points) when the car started braking in avoidance tests for every speed. There is a variation compared with the ideal model of Fig. 14, because the real car speed was not always exactly the same (it was controlled by the driver) and the mannequin was a little closer or further than expected from its theoretical lateral position. The deviation of vehicle speed with respect to the desired speed showed a Normal distribution $(\mu, \sigma)=(0.291,0.549)$ in $\mathrm{m} / \mathrm{s}$ (426 tests, Car A). The real vehicle speed was slightly lower $(0.291 \mathrm{~m} / \mathrm{s})$ than the desired speed. Additionally, some statistical variation can be expected as usual in real tests. Circular markers depict the predicted position of the mannequin when the car should trigger the braking to avoid crash based on the ASM_T criterion. Cross markers depict the position of the mannequin when the car triggered the braking to avoid crash in real tests. Rectangular markers show the positions of the mannequin when the car triggered the braking and resulted in mitigation in real test. We can see that for 10,20 and up to $25 \mathrm{mph}$, the decision is made approximately based on the pure longitudinal ASM_T within the region of $\mathrm{C} \geq 95 \%$. So the model fits very well the test results, but from $25 \mathrm{mph}$ until $30 \mathrm{mph}$ the decision starts to be delayed in some tests, the ASM_T $=0$ criterion is no longer satisfied and the last avoidance test is found about $\mathrm{V}_{0}=12.5 \mathrm{~m} / \mathrm{s}(27.95 \mathrm{mph})$. The figure presents the different limit curves of $\mathrm{C}$, the value $\mathrm{C} \geq 95 \%$ seems to be the limit used in this car if this model of certainty is used. Some mitigation tests observed in the high speed area (about $15 \mathrm{~m} / \mathrm{s}$ ) could have been decided with a lower level of certainty, taking into account the high severity of the impact at higher speed; the injuries can be reduced if the final crash speed is reduced, see [45]. Fig. 15 also shows pedestrian lateral positions indicating how close from the side of the car (situated at $938 \mathrm{~mm}$ from zero) they are.

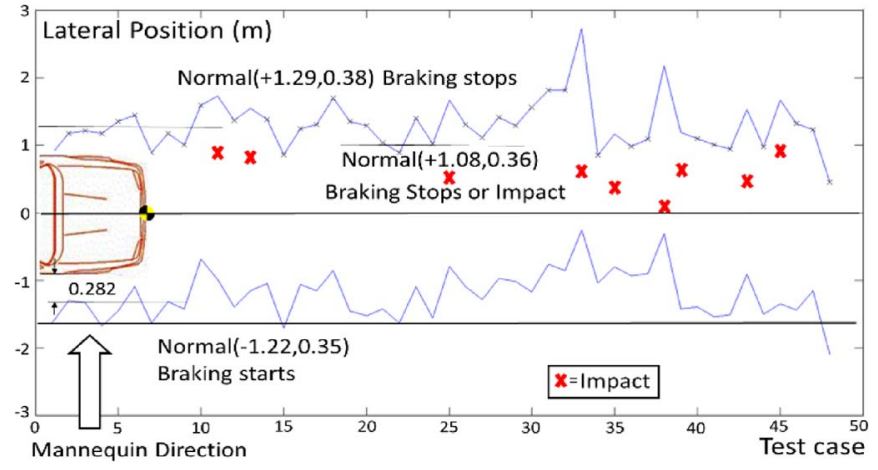

Fig. 16. Lateral mannequin position during braking maneuver in high speed: 40.2 and $48.3 \mathrm{~km} / \mathrm{h}(25$ and $30 \mathrm{mi} / \mathrm{h})$, Car A.

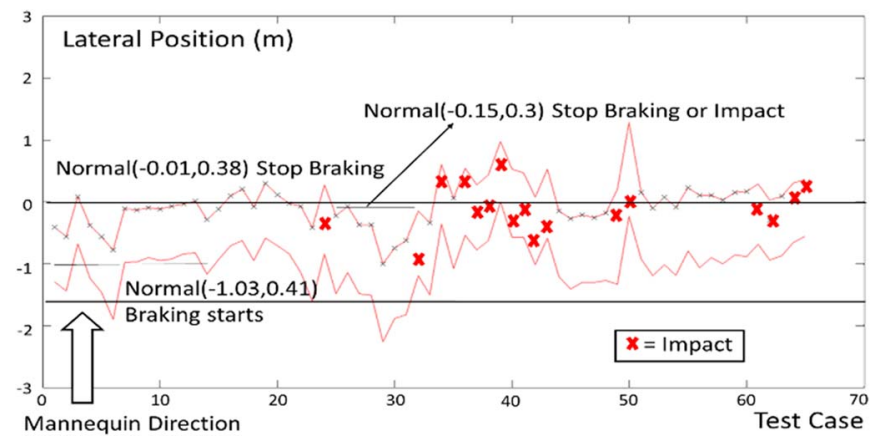

Fig. 17. Lateral mannequin position during braking maneuver in low speed: $16 \mathrm{~km} / \mathrm{h}$ (10 mi/h), Car A.

TABLE II

Pedestrian Distance to Zero Point (m). When the Car. . .

When the car..

\begin{tabular}{|c|c|c|c|c|}
\hline & \multicolumn{2}{|c|}{...starts braking } & \multicolumn{2}{|c|}{... stops braking } \\
\hline & $\begin{array}{l}\text { Low speed } \\
(16 \mathrm{~km} / \mathrm{h})\end{array}$ & $\begin{array}{l}\text { High Speed } \\
(48.3 \mathrm{~km} / \mathrm{h})\end{array}$ & $\begin{array}{l}\text { Low speed } \\
(16 \mathrm{~km} / \mathrm{h})\end{array}$ & $\begin{array}{l}\text { High Speed } \\
(48.3 \mathrm{~km} / \mathrm{h})\end{array}$ \\
\hline Average $\mu$ & -1.03 & -1.22 & 0.01 & 1.08 \\
\hline Std. deviation $\sigma$ & 0.41 & 0.35 & 0.38 & 0.36 \\
\hline
\end{tabular}

Figs. 16 and 17 show the lateral positions of the pedestrian when the braking action starts (lower line) and when it finishes (upper line), in two sets of car A tests at high and low speeds, respectively.

Table II summarizes the numeric results of previous Figs. 16 and 17 .

\section{F. Influence of the Zero Point Position in the Test Results}

Fig. 16 shows that as test vehicle's speed is not constant due to the braking action, the car arrives late to the designed zero point (DZP) located in the middle of the bumper, the pedestrian has already passed and the real zero point (RZP) is beyond the DZP. At low speeds (see Fig. 16), this effect is reduced because both, FED and stopping time are much lower.

If the test had been designed with closer lateral positions of the pedestrian for every value of $\mathrm{x}_{\mathrm{s}}$, assuming for example (see Fig. 11):

$$
y_{1}=v_{p} \cdot x_{s} / V_{0}-b / 2-H .
$$




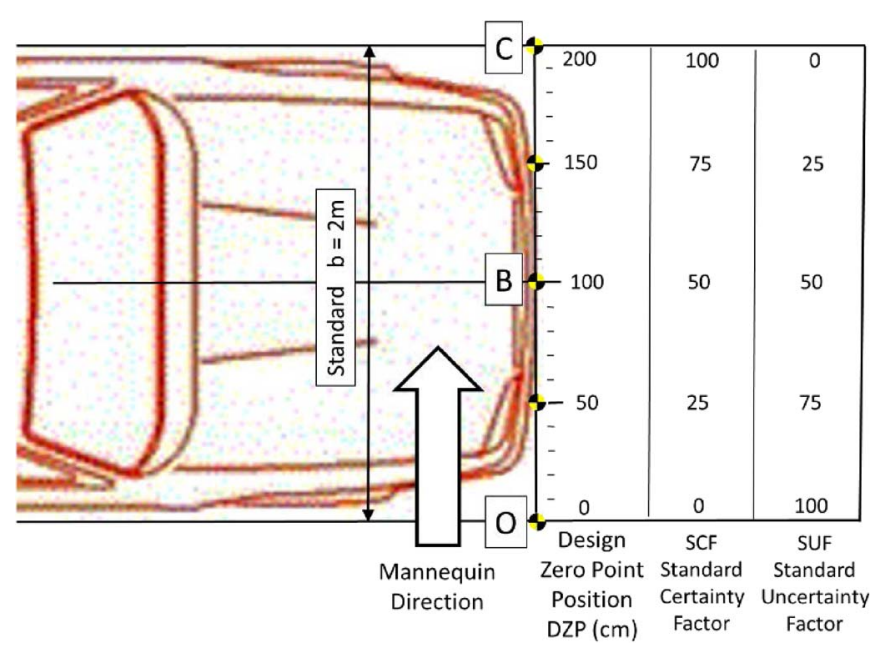

Fig. 18. Proposed scale of certainty in pedestrian AEB tests.

$\mathrm{H}$ being a positive value, the line $\mathrm{u}_{0}-\mathrm{u}_{4}$ in Fig. 14 would have moved upwards and the TSDM would have been higher; the number of full avoidance tests results would then be bigger. But if the TSDM reaches the CSDM, the certainty cannot grow anymore, because if the pedestrian is too close of the IZ when the car is at $\mathbf{x}_{\mathrm{s}}$, the pedestrian could escape just keeping at constant speed, or even running, (see Fig. 11).

All the TASI tests have been designed with the DZP located at the mid-point of the car (Point B in Fig. 18), but in order to consider the behavior of the system in different levels of Certainty, the DZP should have been varied too. Variations in the DZP lead to changes in the decision making, in the RZP and in the test results.

For standardization purposes, a scale of Certainty variation in this kind of tests (see Fig. 18) can be proposed based in the DZP position assuming a standard round value of $b=2 \mathrm{~m}$ (which includes not only the car's width, but part of the pedestrian step), valid for a wide range of passenger cars.

The lateral distance of the DZP from the mid-point B in cm can be used, when designing the test, as an indicator of the certainty level in which the decision has to be made. Associated with that distance, it can be defined a Standard Certainty Factor (SCF) which varies among 0 and 100 in every range of $b$ (valid for different values of $b$ in wider vehicles) and of course it can also be defined a symmetric Standard Uncertainty Factor $(\mathrm{SUF}=100-\mathrm{SCF})$. See Fig. 18 for a more clear understanding.

The DZP or SCF values are not exactly the value of $\mathrm{C}$ in equation (12) but they are directly related, actually looking at the Fig. 15, for speeds among 20 and $30 \mathrm{mph}$, variations of the lateral position of the mannequin of $10 \mathrm{~cm}$ correspond, in a rough approximation, to variations of $\mathrm{C}$ about $5 \%$. This is approximately the same variation of the SCF when DZP changes in Fig. 18.

All tests made by the TASI team and presented in this paper have been carried out with $\mathrm{SCF}=50$. The tests to assess the performance of pedestrian AEB systems can be carried out with different values of designed SCF in every speed, leading to a more accurate assessment of the system. Thus, very conservative strategies, triggering the system only with very high values of C, braking to the full, will get good results when testing with high values of SCF. In return, systems starting a soft braking with lower levels of $\mathrm{C}$ will get good results in tests with low values of SCF. Values of SCF $<0$ can also be possible in nonactivation tests. Values of SCF $>100$ can also make sense for assessment, testing or research.

\section{CONCLUSIONS AND Future Work}

The TASI team has carried out a complete set of tests with two cars equipped with pedestrian AEB systems. In this paper the models of braking and decision making phases for this kind of tests have been presented. The influence of the friction coefficient that can modify the results depending on the track where the tests were carried out and the importance of the transient phase in those low values of initial speed, that lead to moderate levels of final effective decelerations, are two important conditions for these tests. An accurate and standard definition of what is exactly an impact, as the Center of Gravity of the mannequin is retarded or advanced with respect to the feet should be advisable.

The model presented here, can calculate the Active Safety Margin to trigger the tests as an accurate indicator. But the decision making is also dependent on the lateral position of the pedestrian. The importance of an accurate measurement of the lateral position of the mannequin (not only the car position) in this kind of tests, is also identified. The concepts of Certainty and Critical Speed for Decision Making have been modeled. They help to clarify the reasons for the only mitigation results in higher speeds. Although the certainty model presented at Section V-B includes a simple kinematic and statistical description on the pedestrian behavior, it is valid to outline the importance of this concept of Certainty and its influence in the tests results. There is a lack of published data about real behavior of pedestrians in the pre-crash conditions. More testing and research is required in this area, perhaps with the help of driving simulators.

All the tests have been designed to meet both car and mannequin at the zero point assuming no braking action, but some tests with more varied lateral positions of the zero point are required to get a better contrast of the decision making behavior, completing the points in the Fig. 15 leading to a better understanding of this kind of systems in those tests. A scale of certainty variation in the pedestrian AEB tests has been proposed.

When AEB pedestrian protection systems evolve, tests scenarios could include in the future, more complex and challenging situations, for example random longitudinal and lateral combined movement, or partial pedestrians occlusion testing. In that case, the car will continue being subjected to the physics and vehicle dynamics, but the pedestrian model and its related mathematical expressions should be different. The concepts of Certainty and CSDM presented here, could be a valid basis to analyze these situations, in order to compare and improve these AEB systems. A careful step by step approach should be considered, analyzing these more complex scenarios from a well-established basis of models and tests obtained in more simple cases. 


\section{REFERENCES}

[1] D. Gerónimo, A. M. López, A. D. Sappa, and T. Graf, "Survey on pedestrian detection for advanced driver assistance systems," IEEE Trans. Pattern Anal. Mach. Intell., vol. 32, no. 7, pp. 1239-1258, Jul. 2010.

[2] M. Enzweiler and D. M. Gavrila, "Monocular pedestrian detection: Survey and experiments," IEEE Trans. Pattern Anal. Mach. Intell., vol. 31, no. 12, pp. 2179-2195, Dec. 2009.

[3] T. Gandhi and M. M. Trivedi, "Pedestrian protection systems: Issues, survey, and challenges," IEEE Trans. Intell. Transp. Syst., vol. 8, no. 3, pp. 413-430, Sep. 2007.

[4] D. Llorca et al., "Autonomous pedestrian collision avoidance using a fuzzy steering controller," IEEE Trans. Intell. Transp. Syst., vol. 12, no. 2, pp. 390-401, Jun. 2011.

[5] C. G. Keller, T. Dang, H. Fritz, A. Joos, C. Rabe, and D. Gavrila, "Active pedestrian safety by automatic braking and evasive steering," IEEE Trans. Intell. Transp. Syst., vol. 12, no. 4, pp. 1292-1304, Dec. 2011.

[6] D. Llorca, M. A. Sotelo, I. Parra, J. E. Naranjo, M. Gavilán, and S. Álvarez, "An experimental study on pitch compensation in pedestrianprotection systems for collision avoidance and mitigation," IEEE Trans. Intell. Transp. Syst., vol. 10, no. 3, pp. 469-474, Sep. 2009.

[7] K. C. Fuerstenberg, "Pedestrian protection using laser scanners," in Proc IEEE Conf. Intell. Transp. Syst., Vienna, Austria, 2005, pp. 437-442.

[8] I. Parra et al., "Combination of feature extraction methods for SVM pedestrian detection," IEEE Trans. Intell. Transp. Syst., vol. 8, no. 2, pp. 292-307, Jun. 2007.

[9] A. Broggi, M. Bertozzi, A. Fascioli, and M. Sechi, "Shape-based pedestrian detection," in Proc. IEEE Intell. Veh. Symp., Dearborn, MI, USA, Oct. 2000, pp. 328-333.

[10] D. Llorca, I. Parra, M. A. Sotelo, P. Revenga, S. Álvarez, and M. Gavilán, "3D candidate selection method for pedestrian detection on non-planar roads," in Proc. IEEE Intell. Veh. Symp., Istanbul, Turkey, Jun. 2007, pp. 1162-1167.

[11] N. Suganuma and N. Fujiwara, "An obstacle extraction method using virtual disparity image," in Proc. IEEE Intell. Veh. Symp., Istanbul, Turkey, Jun. 2007, pp. 456-461.

[12] D. M. Gavrila and S. Munder, "Multi-cue pedestrian detection and tracking from a moving vehicle," Int. J. Comput. Vis., vol. 73, no. 1, pp. 41-59, Jun. 2007.

[13] Y. Hitoshi, N. Masashi, M. Tsutomu, Y. Naoyuki, and N. Makoto, "Research into evaluation method for pedestrian pre-collision system," presented at the Proceedings 23rd International Technical Conference Enhanced Safety Vehicles (ESV), Seoul, South Korea, May 27-30, 2013, Paper 13-0110.

[14] H. Hayashi, R. Inomata, R. Fujishiro, Y. Ouchi, K. Suzuki, and T. Nanami, "Development of pre-crash safety system with pedestrian collision avoidance assist," presented at the Proceedings 23rd International Technical Conference Enhanced Safety (ESV), Seoul, South Korea, May 27-30, 2013, Paper 13-0271.

[15] R. Labayrade, C. Royere, and D. Aubert, "A collision mitigation system using laser scanner and stereovision fusion and its assessment," in Proc. IEEE Intell. Veh. Symp., Las Vegas, NV, USA, 2005, pp. 441-446.

[16] A. Polychronopoulos, M. Tsogas, A. Amditis, U. Scheunert, L. Andreone, and F. Tango, "Dynamic situation and threat assessment for collision warning systems: The EUCLIDE approach," in Proc. IEEE Intell. Veh. Symp., Parma, Italy, 2004, pp. 636-641.

[17] J. Hillenbrand, V. Schmid, and K. Kroschel, "Situation assessment algorithm for a collision prevention assistant," in Proc. IEEE Intell. Veh. Symp., Las Vegas, NV, USA, 2005, pp. 459-465.

[18] J. Hillenbrand, A. Spieker, and K. Kroschel, "A multilevel collision mitigation approach,” IEEE Trans. Intell. Transp. Syst., vol. 7, no. 4, pp. 528-540, Dec. 2006.

[19] Y. Zhang, D. Danya, T. Z. Qiu, L. Peng, and Z. Yi, "Pedestrian safety analysis in mixed traffic conditions using video data," IEEE Trans. Intell. Transp. Syst., vol. 13, no. 4, pp. 1832-1844, Apr. 2012.

[20] D. Gettman, L. Pu, T. Sayed, and S. Shelby, "Surrogate safety assessment model and validation: Final report," Fed. Highway Admin., McLean, VA, USA, FHWA-HRT-08-051, 2008.

[21] C. Hupfer, "Deceleration to Safety Time (DST)—A useful figure to evaluate. Traffic safety," presented at the ICTCT Conference Proceedings Seminar 3, Dept. Traffic Plan. Eng., Lund Univ., Lund, Sweden, 1997.

[22] C. Salvatore, A. Garcia, C. Rosario, and M. Rojas, "Pedestrian crossing safety improvements: Before and after study using traffic conflict techniques," presented at the Proceedings 4th International Symposium Highway Geometric Design, Valencia, Spain, Jun. 2-5, 2010.

[23] T. L. Staczyk, R. Jurecki, M. Jakiewicz, S. Walczak, and R. Janczur, "Researches on the reaction of a pedestrian stepping into the road from the right side from behind and an obstacle realized on the track," J. KONES Powertrain Transp., vol. 18, no. 1, pp. 1-8, 2011.

[24] T. L. Staczyk, Z. Lozia, R. Jurecki, and W. Pieniek, "Studies of reactions of drivers in simulated accident situations," Zeszyty Naukowe Instytutu Pojazdów Politechniki Warszawskiej, Warsaw, Poland, Nr 1(77)/2010, s. 27-52, 2010.

[25] T. L. Staczyk, R. Jurecki, W. Pieniek, M. Jakiewicz, M. P. Karenda, and S. Wolak, "Studies on reactions of drivers to the vehicle approaching from the right side, carried on a car track," Zeszyty Naukowe Instytutu Pojazdów Politechniki Warszawskiej, Warsaw, Poland, Nr 1(77)/2010, s. 307-319, 2010.

[26] X. Zhang, P. Chen, H. Nakamura, and M. Asano, "Modelling pedestrian walking peed at signalized crosswalks considering crosswalk length and signal timing," in Proc. Eastern Asia Soc. Transp. Stud., 2013, vol. 9.

[27] S. Chandra, R. Rastogi, V. R. Das, and T. Ilango, "Pedestrian behaviour under varied traffic and spatial conditions," presented at the European Transport, New Delhi, India, no. 56, 2014, Paper 5, ISSN 1825-3997.

[28] M. Montufar, J. Arango, M. Porter, and S. Nakagawa, "Pedestrians' normal walking speed and speed when crossing a street," Transp. Res. Rec. TRB, Nat. Res. Council, Washington, DC, USA, 2002, pp. 90-97.

[29] M. Fransen, J. Heussler, E. Margiotta, and J. Edmonds, "Quantitative gait analysis comparison of rheumatoid arthritic and non-arthritic subjects," Australian J. Phisiotherapy, vol. 40, no. 3, pp. 191-199, 1994.

[30] S. C. Miff, D. S. Childress, S. A. Gard, M. R. Meier, A. H. Hansen, and J. Brown, "Temporal symmetries during gait initiation and termination in nondisabled ambulators and in people with unilateral transtibial limb loss," J. Rehabil. Res. Develop., vol. 42, no. 2, pp. 175-182, Mar./Apr. 2005.

[31] S. Kohler, M. Goldhammer, S. Bauer, K. Doll, U. Brunsmann, and K. Dietmayer, "Early detection of the pedestrian's intention to cross the street," in Proc. 15th Int. IEEE Conf. ITS, Anchorage, AK, USA, Sep. 16-19, 2012, pp. 1759-1764.

[32] S. P. Hoogendoorn and P. H. L. Bovy, "Simulation of pedestrian flows by optimal control and differential games," Optim. Control Appl. Methods, vol. 24, pp. 153-172, 2003.

[33] C. Wakim, S. Capperon, and J. Oksman, "A Markovian model of pedestrian behavior," in Proc. IEEE Int. Conf. Syst., Man, Cybern., Oct. 2004, pp. 4028-4033.

[34] E. Rosén and U. Sander, "Pedestrian fatality risk as a function of car impact speed," Accident Anal. Prevention, vol. 41, pp. 536-542, 2009.

[35] S. Chien, Q. Yi, Y. Chen, A. Gholigafari, and R. Sherony, "Method of selecting test scenarios for pedestrian forward looking pre-collision system evaluation," presented at the SAE World Congress Exhibition, Detroit, MI, USA, Apr. 2014, Paper 14AC-0125.

[36] M. Yanagisawa, E. Swanson, and W. G. Najm, "Target crashes and safety benefits estimation methodology for pedestrian crash avoidance/ mitigation systems," Nat. Highway Traffic Safety Admin., Washington, DC, USA, 2014.

[37] S. Chien, L. Dong, Q. Yi, Y. Chen, R. Sherony, and H. Takahashi, "Joint motion pattern of limb moving mannequins for active safety vehicle tests," presented at the 23rd ESV Conference, Seoul, South Korea, May 27-30, 2013.

[38] Q. Yi et al., "Mannequin development for pedestrian pre-collision system evaluation," in Proc. IEEE 17th ITSC, Qingdao, China, 2014, pp. 1626-1631.

[39] B. Tang, S. Chien, and Y. Chen, "Obtain a simulation model of a pedestrian collision imminent braking system based on the vehicle testing data," in Proc. IEEE 17th ITSC, Qingdao, China, 2014, pp. 1650-1655.

[40] S. Chien, L. Dong, Q. Yi, Y. Chen, R. Sherony, and H. Takahashi, "Joint motion pattern of limb moving mannequins for active safety vehicle tests," presented at the 23rd ESV Conference, Seoul, South Korea, May 27-30, 2013.

[41] A. López, R. Sheroni, S. Chien, L. Li, Q. Yi, and Y. Chen, "Analysis of the braking behaviour in pedestrian automatic emergency braking," in Proc. IEEE 18th Int. Conf. Intell. Transp. Syst., Las Palmas de Gran Canaria, Spain, Sep. 2015, pp. 1117-1122.

[42] D. Good, S. Chien, L. Li, and Y. Chen, "Preliminary benefit analysis for pedestrian crash imminent braking systems," in Proc. IEEE 18th Int. Conf. Intell. Transp. Syst., Las Palmas de Gran Canaria, Spain, Sep. 2015, pp. 1123-1128.

[43] A. López, P. Vélez, and C. Moriano, "Método de procesamiento rápido de las ecuaciones de la dinámica vehicular mediante polinomios de Chebyshev," Encuentro de Algebra Computacional y Aplicaciones (EACA), Sevilla, Spain, 2006.

[44] A. López, C. Moriano, J. L. Olazagoitia, and F. J. Páez, "Fast computing on vehicle dynamics," IEEE/ASME Trans. Mechatronics, no. 99, pp. 2563-2574, Feb. 2015. 


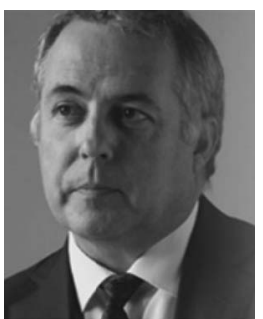

Alberto López Rosado (M'14) received the Master's degree in industrial engineering (mechanical engineering intensification) and the Ph.D. degree from the Universidad Politécnica de Madrid, Madrid, Spain.

$\mathrm{He}$ is a Professor of mechanisms and machine theory and vehicle engineering. He is also a Visiting Professor with the Transportation Active Safety Institute, Indiana University-Purdue University Indianapolis, Indianapolis, IN, USA. His research areas of interest include active safety, real-time vehicle dynamics, tire models, and electric vehicle simulation.

Dr. López Rosado is an active member of the SAE.

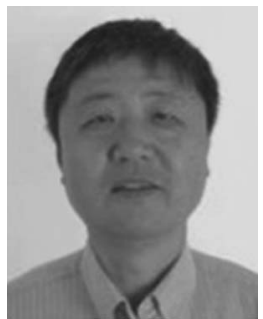

Stanley Chien (S'84-M'89-SM'12) received the $\mathrm{Ph} . \mathrm{D}$. degree in electrical and computer engineering from Purdue University, West Lafayette, IN, USA, in 1989.

$\mathrm{He}$ is currently a Professor with the Department of Electrical and Computer Engineering, Indiana University-Purdue University Indianapolis, Indianapolis, IN. His research interests include vehicle active safety, dynamic load balancing of parallel computing, software engineering, and robotics.

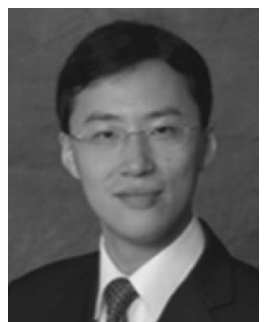

Lingxi Li (S'04-M'08-SM'13) received the Ph.D. degree in electrical and computer engineering from the University of Illinois at Urbana-Champaign, Champaign, IL, USA, in 2008.

Since August 2008, he has been with Indiana University-Purdue University Indianapolis, Indianapolis, IN, USA, where he is currently an Associate Professor in electrical and computer engineering. His research interests include modeling, analysis, control, and optimization of complex systems, intelligent transportation systems and intelligent vehicles, discrete event systems, active safety systems, and human factors.

Dr. Li has served as a Program Chair for the 2011 and 2013 IEEE International Conference on Vehicular Electronics and Safety and has been serving as an Associate Editor for the IEEE TRANSACTIONS ON INTELLIGENT TRANSPORTATION SYSTEMS since 2009.

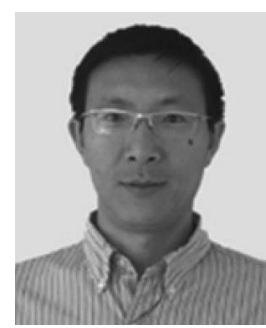

Qiang Yi (M'13) received the Ph.D. degree in mechanical engineering from Tsinghua University, Beijing, China, in 2010

$\mathrm{He}$ is currently a Visiting Research Assistant Professor with the Department of Electrical and Computer Engineering, Indiana University_-Purdue University Indianapolis, Indianapolis, IN, USA. His research interests include vehicular active safety, intelligent bionic and manipulation robots, mechanical system dynamics and control, and integration of mechatronic systems.

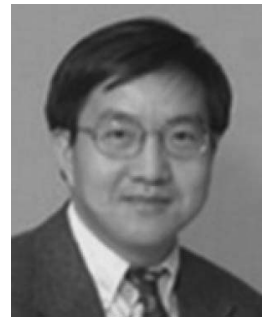

Yaobin Chen received the B.S. degree from Nanjing Institute of Technology, Nanjing, China, in 1982 and the M.S. and Ph.D. degrees from Rensselaer Polytechnic Institute, Troy, NY, USA, in 1986 and 1988, respectively, all in electrical engineering.

$\mathrm{He}$ is a Professor and Chair of electrical and computer engineering with the Purdue School of Engineering and Technology, Indiana UniversityPurdue University Indianapolis, Indianapolis, IN, USA. He is also the Head and Director of the Transportation Active Safety Institute. He has published more than 90 technical papers in refereed journals and conference proceedings. His areas of research interest include modeling, control, and optimization of advanced transportation and vehicle systems, active safety control systems, intelligent systems, and applications.

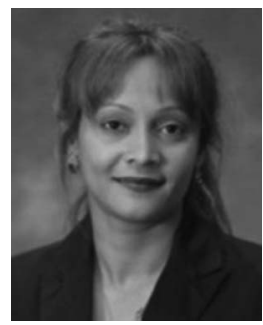

Rini Sherony (M'04) received the Master's degree in electrical engineering and computer science from Kettering University, Flint, MI, USA, in 1997.

She is currently with Toyota's Collaborative Safety Research Center, Ann Arbor, MI, where she leads several projects in vehicle active safety. Her area of expertise is vehicle active safety system design and evaluation and crash data analysis. 